\title{
Awareness of postpolypectomy surveillance guidelines: A nationwide survey of colonoscopists in Canada
}

\author{
Harmke van Kooten* MSc ${ }^{1}$, Vincent de Jonge* $\mathrm{MSc}^{1}$, Eline Schreuders MSc ${ }^{1}$, Jerome Sint Nicolaas MSc ${ }^{1}$, \\ Monique E van Leerdam MD PhD ${ }^{1}$, Ernst J Kuipers MD PhD ${ }^{1,2}$, Sander JO Veldhuyzen van Zanten MD PhD
}

H van Kooten, V de Jonge, E Schreuders, et al. Awareness of postpolypectomy surveillance guidelines: A nationwide survey of colonoscopists in Canada. Can J Gastroenterol 2012;26(2):79-84.

INTRODUCTION: Due to the increasing demand for colonoscopy, adherence to postpolypectomy surveillance guidelines is important. Suboptimal compliance can lead to unnecessary risks and ineffective use of resources.

OBJECTIVE: To determine the awareness of and adherence to postpolypectomy surveillance guidelines among members of the Canadian Association of Gastroenterology (CAG).

METHODS: A survey describing 14 clinical cases was mailed to all physician members $(n=411)$ of the CAG. Respondents were required to recommend a surveillance interval and a reason for his or her choice. RESULTS: A total of 150 colonoscopists (37\%) completed the survey. Adherence to the guidelines varied from $23 \%$ to $96 \%$ per clinical scenario (median 63\%). Recommended surveillance intervals were too short in $0 \%$ to $60 \%$ of the different cases (median $8 \%$ ). The recommended interval was most often $(60 \%)$ too short for a patient with one tubular adenoma with high-grade dysplasia. Surveillance intervals were too long in $4 \%$ to $75 \%$ of the cases (median $9 \%$ ). The recommended interval was most often too long in a patient with a villous adenoma $15 \mathrm{~mm}$ in size and removed piecemeal (75\%). Most often, recommendations were reported to be based on guidelines (median $74 \%$; range $31 \%$ to $94 \%$ ). However, in nine of 14 cases, more than $10 \%$ (median $18 \%$; range $12 \%$ to $38 \%$ ) of the respondents stated that their recommendation was based on guidelines, but did not provide the appropriate surveillance interval.

CONCLUSIONS: Compliance to colonoscopy surveillance guidelines is suboptimal and reflects both overuse and underuse. The results show that awareness about the content of guidelines needs to be raised and strategies implemented to increase adherence.

Keywords: Adenomatous polyps; Cancer prevention; Colonoscopy; Guidelines; Surveillance

Oolorectal cancer (CRC) is the third most commonly diagnosed type of cancer, and the second leading cause of cancer-related death in both men and women in Canada (1). It has been shown that screening of asymptomatic, average-risk individuals and persons at increased risk, such as those with a positive family history of CRC, can reduce CRC-related mortality (2-4). Therefore, many institutions recommend screening for $\mathrm{CRC}$, although different approaches are advised (5-7).

When a polyp is found at index screening, it is generally removed to establish its histology and to determine the completeness of removal. Despite the removal of adenomas, they are still commonly found during follow-up (FU) procedures (8). Adenomas detected during surveillance
La connaissance des lignes directrices de surveillance après la polypectomie : une enquête nationale auprès des coloscopistes canadiens

INTRODUCTION : Étant donné la demande croissante de coloscopies, il est important d'observer les lignes directrices de surveillance après la polypectomie. Une observance sous-optimale peut susciter des risques inutiles et une utilisation inefficace des ressources.

OBJECTIF : Déterminer la connaissance et l'observance des lignes directrices de surveillance après la polypectomie chez les membres de l'Association canadienne de gastroentérologie (ACG).

MÉTHODOLOGIE : Tous les membres médecins de l'ACG $(\mathrm{n}=411)$ ont reçu un sondage par la poste décrivant 14 cas cliniques. Les répondants devaient recommander un intervalle de surveillance et donner la raison de leur choix.

RÉSULTATS : Au total, 150 coloscopistes (37\%) ont répondu au sondage. L'observance des lignes directrices variait entre $23 \%$ et $96 \%$ selon le scénario clinique (médiane de $63 \%$ ). Les intervalles de surveillance recommandés étaient trop courts dans $0 \%$ à $60 \%$ des divers cas (médiane de $8 \%$ ). L'intervalle recommandé était généralement trop court (60\%) chez un patient ayant un adénome tubuleux et une dysplasie grave. Les intervalles de surveillance étaient trop longs dans $4 \%$ à $75 \%$ des cas (médiane de $9 \%$ ). L'intervalle recommandé était généralement trop long chez un patient ayant un adénome villeux de $15 \mathrm{~mm}$, et l'ablation était partielle (75\%). La plupart du temps, les répondants déclaraient fonder leurs recommandations sur les lignes directrices (médiane de $74 \%$; plage de $31 \%$ à $94 \%$ ). Cependant, dans neuf des 14 cas, plus de $10 \%$ (médiane de $18 \%$; plage de $12 \%$ à $38 \%$ ) des répondants ne fournissaient pas l'intervalle de surveillance pertinent même s'ils déclaraient que leur recommandation se fondait sur les lignes directrices.

CONCLUSIONS : L'observance des lignes directrices de surveillance de la coloscopie est sous-optimale et reflète à la fois une surutilisation et une sous-utilisation. D'après les résultats, il faut mieux faire connaître le contenu des lignes directrices et mettre des stratégies en œuvre pour en accroître l'observance.

colonoscopies may include both missed adenomas and recurrent adenomas. The main risk factors for adenoma recurrence are hereditary CRC syndromes, older patient age, detection of $\geq 3$ adenomas at index endoscopy, large adenomas ( $>10 \mathrm{~mm}$ ), and adenomas exhibiting villous histology or high-grade dysplasia (HGD) (9). Surveillance recommendations are, therefore, tailored to baseline findings.

Because the demand for endoscopy is increasing, adherence to the guidelines for postpolypectomy surveillance intervals is of paramount importance. Because endoscopic capacity is limited, performing too many surveillance colonoscopies may hinder access to endoscopic procedures, and decreases the cost effectiveness of CRC screening programs (10-11). Moreover, because rare but serious complications

*Authors who contributed equally to the manuscript

${ }^{1}$ Department of Gastroenterology and Hepatology; ${ }^{2}$ Department of Internal Medicine, Erasmus MC University Medical Center, Rotterdam,

The Netherlands; ${ }^{3}$ Division of Gastroenterology, University of Alberta Hospital, Edmonton, Alberta

Correspondence: Dr Vincent De Jonge, Department of Gastroenterology and Hepatology, Erasmus MC University Medical Center, Room Hs 306,

's Gravendijkwal 230, PO Box 2040, 3000 CA Rotterdam, the Netherlands. Telephone 31-107033040, fax 31-107034682,

e-mail v.dejonge@erasmusmc.nl

Received for publication April 14, 2011. Accepted June 26, 2011 


\section{TABLE 1}

Respondent characteristics $(n=139)$

\begin{tabular}{lc}
\hline Age, years, mean \pm SD & $47.7 \pm 10.1$ \\
Specialty & $137(97.2)$ \\
Gastroenterologist & $4(2.8)$ \\
Internist & $16.9 \pm 9.9$ \\
Experience in performing colonoscopy, years, & \\
$\quad$ mean \pm SD (n=136) & \\
Practice setting & $51(37.0)$ \\
Private individual practice & $21(15.2)$ \\
Private group practice & $66(47.8)$ \\
University practice & \\
Average number of colonoscopies performed per month & $1(0.7)$ \\
None & $1(0.7)$ \\
$1-10$ & $5(3.7)$ \\
$11-20$ & $21(15.7)$ \\
$21-30$ & $18(13.4)$ \\
$31-40$ & $24(17.9)$ \\
$41-50$ & $64(47.8)$ \\
\hline 51 & \\
\hline
\end{tabular}

Data presented as $n(\%)$, unless otherwise indicated

are associated with colonoscopy, surveillance at intervals that are too short exposes patients to unnecessary risks $(12,13)$. Underutilization may also be a problem because patients may be at increased risk of developing CRC. Several studies have shown that many patients do not receive surveillance colonoscopy at the appropriate interval or do not receive surveillance colonoscopy at all $(14,15)$. These studies were performed before the most recent publication of postpolypectomy guidelines from the American Gastroenterological Association (AGA) in 2008 and, since then, the attention to CRC screening and surveillance has increased greatly (6).

The failure to adhere to postpolypectomy surveillance guidelines may be due to a lack of awareness or familiarity with the guidelines (16-18). Another possible reason for physicians to deviate from the recommendations is disagreement with the guidelines (19). Either explanation requires a different approach to improve surveillance and optimize the use of resources.

The present study aimed to determine the awareness of members of the Canadian Association of Gastroenterology (CAG) of postpolypectomy surveillance guidelines. In addition, factors associated with a physician's choice to deviate from the guidelines were assessed.

\section{METHODS}

A survey was mailed to all 411 registered physician members of the CAG in June 2010. The survey was also sent by e-mail in the CAG Member Newsletter of both June and July 2010. Invitees were offered the opportunity to complete the survey online or by mail using a selfaddressed, postage-paid envelope. Anonymity of the data was guaranteed to the responders because the survey was conducted by the CAG, while the responses were collected by researchers who had no access to the CAG mailing list.

\section{Questionnaire}

The questionnaire focused on the awareness of colonoscopists about current postpolypectomy surveillance guidelines. For that purpose, an adapted questionnaire previously used in the Netherlands was used (16). The first part of the questionnaire contained seven questions on demographic characteristics. The second part assessed the recommended surveillance intervals of the colonoscopists in 14 hypothetical clinical cases of index colonoscopies. To match the different scenarios addressed in the guidelines, each case differed in endoscopic finding, including risk factors such as number, size, histology or grade of dysplasia of the polyps. In all cases, the patient was assumed to be in good health and to have undergone his or her first colonoscopy in which cecal intubation had been achieved, bowel preparation was adequate and adenomas had been completely removed en-block unless indicated otherwise. In each case, the physician was asked if he or she would recommend surveillance colonoscopy at all and, if so, at what interval. Second, the respondents were asked why they choose this particular time interval for FU.

All data were entered into a database. For each case, the appropriate surveillance interval was determined. The CAG guidelines on CRC surveillance published in 2004 (5) recommend surveillance colonoscopy in three years to patients with $\geq 3$ adenomas, and in five years in patients with one to two tubular adenomas $\leq 10 \mathrm{~mm}$ in size. For all other cases, baseline features such as advanced adenoma characteristics (adenomas $>10 \mathrm{~mm}$, or containing villous histology or HGD) should be taken into consideration, and surveillance intervals should be based on clinical judgment. Because more evidence about the risk of adenoma recurrence has become available since 2004, it was decided to use the most recent guidelines from the AGA (6) as is performed in daily clinical practice. These guidelines provide clear-cut recommendations for surveillance intervals for different index polyp characteristics such as size of the polyp(s), number of polyps, grade of dysplasia and histology.

The recommendations were divided into four categories: no FU; appropriate FU; FU at a shorter interval than recommended by the guidelines; and FU at a longer interval than recommended by the guidelines. Recommendations \pm 3 months around the interval as recommended by the AGA guidelines were considered to be appropriate.

\section{Statistical analyses}

Statistical analyses were conducted using SPSS version 18.0 (IBM Corporation, USA). Descriptive statistics were used to analyze and report the data. Mean and SD were calculated for normally distributed data, while the median and interquartile range (IQR) were calculated for non-normally distributed data. Analyses of the recommended intervals were performed on each case separately. For further analyses, the cases were divided into categories of low-risk (nonadvanced lesions: cases 1, 2 and 14), high-risk (advanced lesions: cases 3, 4, 5, 6 and 12) and patients with a positive family history of CRC (cases 8 and 9). Differences in outcome between groups of patients were calculated using the Student's $t$ test for continuous data and the $\chi^{2}$ or Fisher's exact test for categorical data, when appropriate.

\section{RESULTS}

A total of $150 \mathrm{CAG}$ members returned the survey, yielding a response rate of $37 \%$. Responders and nonresponders did not differ with respect to sex $(81 \%$ versus $76 \%$ male $[\mathrm{P}=0.11])$ or geographic distribution. Eight respondents (seven pediatric gastroenterologists and one hepatologist) did not fully complete the questionnaire because the cases were not applicable to their practice. These were excluded from further analysis, leaving 142 respondents for final analysis.

\section{Demographic data of the respondents}

Table 1 summarizes the characteristics of the respondents. Their mean $( \pm \mathrm{SD})$ age was $47.7 \pm 10.1$ years, and $81 \%$ were men. The majority (97\%) were gastroenterologists, and the remainder (3\%) were internists. Almost one-half of the respondents (48\%) were employed at a university hospital. The mean length of experience in performing colonoscopy was $16.9 \pm 9.9$ years (range one to 38 years).

\section{Surveillance colonoscopy recommendations}

Overall, the mean percentage of appropriate recommendations was $63 \%$ (range 23\% to 96\%). The proportion of appropriate recommendations was independent of the years of colonoscopy experience, although physicians with more than 12 years of experience had a lower percentage of total appropriate recommendations compared with physicians with experience of between eight and 12 years (61\% versus $74 \%[\mathrm{P}<0.1])$. Physicians employed at an academic centre did have 


\begin{tabular}{|c|c|c|c|c|c|c|c|}
\hline \multirow[b]{2}{*}{ Patient age, clinical scenario } & \multirow[b]{2}{*}{$\begin{array}{l}\text { Respondents, } \\
\mathbf{n}\end{array}$} & \multirow{2}{*}{$\begin{array}{c}\text { Interval } \\
\text { recommended } \\
\text { by guidelines }\end{array}$} & \multirow{2}{*}{$\begin{array}{c}\text { Correct } \\
\text { recommendation } \\
\text { chosen, } \%\end{array}$} & \multicolumn{3}{|c|}{ Follow-up, \% } & \multirow{2}{*}{$\begin{array}{c}\text { Recommended } \\
\text { interval, } \\
\text { years, } \\
\text { median (IQR) }\end{array}$} \\
\hline & & & & None & $\begin{array}{c}\text { Too } \\
\text { early }\end{array}$ & $\begin{array}{l}\text { Too } \\
\text { late }\end{array}$ & \\
\hline 55 years, 2 hyperplastic polyps & 141 & 10 years & 61.7 & 28.4 & 9.9 & - & $10.0(0.0-10.0)$ \\
\hline 50 years, 1 tubular adenoma $7 \mathrm{~mm}$ in size & 142 & 5 to 10 years & 93.0 & - & 7.0 & - & $5.0(5.0-5.0)$ \\
\hline 50 years, 1 tubular adenoma $12 \mathrm{~mm}$ in size & 140 & 3 years & 64.3 & - & 2.9 & 32.9 & $3.0(3.0-5.0)$ \\
\hline 50 years, 1 villous adenoma $15 \mathrm{~mm}$ in size & 139 & 3 years & 62.6 & - & 25.0 & 11.5 & $3.0(2.5-3.0)$ \\
\hline 65 years, 5 tubular adenomas, all $<10 \mathrm{~mm}$ in size & 140 & 3 years & 79.3 & - & 12.1 & 8.6 & $3.0(3.0-3.0)$ \\
\hline 50 years, 12 tubular adenomas, all $<10 \mathrm{~mm}$ in size & 139 & $<3$ years & 96.4 & - & - & 3.6 & $1.5(1.0-3.0)$ \\
\hline 65 years, postcurative CRC resection (T2NOMO) & 139 & 1 year & 74.8 & - & 0.7 & 24.5 & $1.0(1.0-1.0)$ \\
\hline 45 years, 1 first-degree relative with CRC younger than 60 years & 139 & 5 years & 92.1 & 0.7 & 2.2 & 5.0 & $5.0(5.0-5.0)$ \\
\hline 52 years, 1 first-degree relative with CRC older than 60 years & 140 & 10 years & 40.7 & 3.6 & 55.7 & - & $5.0(5.0-10.0)$ \\
\hline $\begin{array}{l}50 \text { years, } 1 \text { sessile villous adenoma } 15 \mathrm{~mm} \text { in size, removed } \\
\text { piecemeal }\end{array}$ & 139 & 2 to 6 months & 25.2 & - & - & 74.8 & $1.4(0.8-2.0)$ \\
\hline $\begin{array}{l}55 \text { years, } 1 \text { villous adenoma } 9 \mathrm{~mm} \text { in size and inadequate bowel } \\
\text { preparation }\end{array}$ & 139 & NA & NA & NA & NA & NA & $1.0(1.0-2.0)$ \\
\hline 50 years 1 tubular adenoma $8 \mathrm{~mm}$ in size, HGD & 139 & 3 years & 30.2 & - & 59.7 & 10.1 & $1.0(1.0-3.0)$ \\
\hline 85 years, 1 villous adenoma $6 \mathrm{~mm}$ in size, LGD & 139 & 3 years & 23.0 & 58.3 & 10.8 & 7.9 & $0.0(0.0-3.0)$ \\
\hline $\begin{array}{l}60 \text { years, } 4 \text { tubular adenomas on screening, } 1 \text { hyperplastic polyp } \\
\text { at first surveillance }\end{array}$ & 138 & 5 years & 81.9 & - & 8.0 & 10.1 & $5.0(5.0-5.0)$ \\
\hline
\end{tabular}

CRC Colorectal cancer; HGD High-grade dysplasia; IQR Interquartile range; LGD Low-grade dysplasia; NA Not applicable; TNM Tumour, node, metastasis

the same percentage of appropriate recommendations compared with physicians in nonacademic settings (66\% versus $62 \%[\mathrm{P}=0.2])$. The mean percentage of correct recommendations in nonadvanced cases was $79 \%$ (range $62 \%$ to $93 \%$ ). The median recommended surveillance interval in nonadvanced cases was five years (IQR 5 to 10 years). No differences in the overall percentage of appropriate recommendation for nonadvanced cases were observed between physicians with different years of colonoscopy experience, or whether physicians were employed at an academic centre $(P>0.1)$.

When advanced adenomas were present at index colonoscopy, correct recommendations were provided by a mean of $54 \%$ of respondents (range 23\% to 96\%). The median recommended interval in advanced cases was three years (IQR 1 to 3 years). No differences in the overall percentage of appropriate recommendations for advanced cases were observed among physicians with different years of colonoscopy experience, or different practice setting $(\mathrm{P}>0.1)$.

Per physician, recommendations were correct in a mean of $63 \%$ of cases (range $23 \%$ to $100 \%$ ). Only two respondents (1.4\%) recommended the appropriate interval for surveillance colonoscopy in all cases.

Table 2 summarizes the appropriateness of the recommendations given by the physicians in each case. The highest compliance to the guidelines was found in the case of a 55-year-old woman with 12 tubular adenomas all $<10 \mathrm{~mm}$ in size: $96 \%$ of the respondents gave a recommendation for $\mathrm{FU}$ within three years (median interval two years, IQR 1 to 3 years), while $4 \%$ offered the pateint a surveillance colonoscopy after an interval that was too long. The lowest adherence to the guidelines was found in the case of a 50-year-old woman with a sessile villous adenoma $15 \mathrm{~mm}$ in size, removed piecemeal. Only 25\% of the respondents adhered to the guidelines by giving a recommendation for FU in two to six months, while the majority (75\%) recommended surveillance colonoscopy after an interval that was too long (median interval 1.4 years; IQR 1 to 2 years).

The patient with a tubular adenoma $>10 \mathrm{~mm}$ in size (50-year-old man with one tubular adenoma $12 \mathrm{~mm}$ in size) was recommended to undergo surveillance colonoscopy after three years, as recommended by the guidelines, by $64 \%$ of the respondents (median interval 3 years; IQR 3 to 5 years), while $33 \%$ recommended surveillance colonoscopy after a longer interval. In cases in which a large villous adenoma was found (50-year-old woman with one villous adenoma $15 \mathrm{~mm}$ in size), the recommendation for surveillance colonoscopy was in agreement with the guidelines in $63 \%$ (median interval three years, IQR 2.5 to 3.0 years). In this case, $25 \%$ of the respondents recommended surveillance colonoscopy sooner than recommended by the guidelines.

In the case of an 85-year-old male patient, a 50-year-old man with no adenomas at index endoscopy and a 52 -year-old patient with one first-degree relative diagnosed with CRC who was older than 60 years of age, $58 \%, 28 \%$ and $4 \%$ of the respondents, respectively, did not recommend surveillance colonoscopy.

There are no clear-cut guidelines for when to perform repeat colonoscopy in cases of inappropriate bowel preparation. The case of the 55 -year-old man with inadequate bowel preparation demonstrated that surveillance colonoscopy is recommended by physicians after a short time (median 1 year, IQR 1 to 2 years).

Reason for surveillance interval recommendation

Table 3 summarizes the reason from the respondents for recommending a particular surveillance interval. In most cases, the majority of the respondents stated that they followed the guidelines.

In the case of a 50-year-old woman with a villous adenoma $15 \mathrm{~mm}$ in size removed piecemeal (case 10), $47 \%$ of the respondents recommeded not following the guidelines based on their clinical experience. When respondents stated that they were following the guidelines, their recommendation was correct in most cases. However, in nine cases (cases 3, 4, 5, 7, 9, 10, 12, 13 and 14), more than $10 \%$ of the respondents (range $12 \%$ to $38 \%$ ) stated that their recommendation was based on the guidelines, but they did not give the appropriate recommendation for FU, as shown in Table 3.

Despite the absence of guidelines in the case of a 55 -year-old male patient with one villous adenoma $9 \mathrm{~mm}$ in size but poor bowel preparation, $13 \%$ stated that they followed the guidelines in their recommendation.

\section{DISCUSSION}

Due to the risk of adenoma recurrence after polypectomy, optimal prevention of CRC after adenoma removal requires additional surveillance procedures $(9,10)$. Guidelines aim for maximal prevention with available resources, which for endoscopy capacity, are limited. Surveillance colonoscopy at appropriate intervals is of paramount importance to prevent unnecessary risks, increased costs and discomfort to the patient. 
TABLE 3

Reasons for recommending a particular interval for follow-up colonoscopy

\begin{tabular}{|c|c|c|c|c|c|c|}
\hline \multirow[b]{2}{*}{ Case } & \multirow{2}{*}{$\begin{array}{c}\text { No } \\
\text { follow-up }\end{array}$} & \multirow{2}{*}{$\begin{array}{c}\begin{array}{c}\text { Guideline - adequate } \\
\text { interpretation }\end{array} \\
\end{array}$} & \multirow{2}{*}{$\begin{array}{c}\text { Guideline but incorrect } \\
\text { interpretation* }\end{array}$} & \multicolumn{2}{|c|}{ Based on } & \multirow[b]{2}{*}{ Other reason } \\
\hline & & & & Clinical experience & Recent evidence & \\
\hline 1 & 28.8 & 48.2 & 2.2 & 7.2 & 4.3 & 9.4 \\
\hline 2 & - & 83.1 & 3.5 & 7.7 & 5.6 & - \\
\hline 4 & - & 56.5 & 17.4 & 20.3 & 3.6 & 2.2 \\
\hline 5 & - & 71.3 & 12.2 & 11.5 & 3.6 & 1.4 \\
\hline 6 & - & 40.6 & 2.9 & 40.6 & 2.9 & 13.0 \\
\hline 8 & - & 88.6 & 5.0 & 4.3 & 1.4 & 0.7 \\
\hline 9 & 1.5 & 36.8 & 37.5 & 16.9 & 2.2 & 5.1 \\
\hline 10 & - & 11.7 & 29.2 & 47.4 & 2.9 & 8.0 \\
\hline 11 & - & 12.9 & NA & 82.0 & 0.7 & 4.3 \\
\hline 12 & - & 24.8 & 24.1 & 42.3 & 2.9 & 5.8 \\
\hline 13 & 38.8 & 14.4 & 16.5 & 24.5 & 1.4 & 4.3 \\
\hline
\end{tabular}

Data presented as \%. *Colonoscopist stated that his or her recommendation was based on the guidelines, but did not provide the appropriate recommendation for follow-up

Our study showed that a significant proportion of respondents did not follow the guidelines or were not paticularly familiar with them. Adherence to the guidelines varied widely (from 23\% to 96\%) for different clinical scenarios. In four cases, inappropriate surveillance recommendations were given in $\geq 50 \%$. Furthermore, in most cases, the majority of respondents said they based their recommendations on the guidelines. However, in nine of the 14 cases, $12 \%$ to $38 \%$ of the colonoscopists stated that their recommendation was based on the guidelines, but they did not give the appropriate recommendation. These results suggest that an educational intervention that raises awareness and knowledge about the guidelines would be beneficial.

The lack of recent, explicit guidelines in Canada based on the latest evidence is a possible reason for the low adherence to the recommended intervals for surveillance colonoscopy that we observed. The CAG guidelines on adenoma surveillance were last updated in 2004 (5). In 2008, the AGA republished its guidelines on postpolypectomy surveillance (6). These are tailored to the presence of risk factors on index colonoscopy. Because there has been no change in the Canadian guidelines based on recent evidence, most physicians use the AGA guidelines in daily practice.

Other reasons that might explain the marked variation in adherence to the guidelines may be that the guidelines are not entirely clear, subject to variable interpretation, not compatible with daily clinical practice or not practicable (20).

No specific pattern in appropriateness of recommendations for patients with advanced or nonadvanced adenomas was found. This is consistent with previous research that showed that, in both cases, colonoscopies are often performed too soon $(16-18,21)$. The most important difference between those studies and our findings is that we found both overuse and underuse of endoscopic resources, while the previous reports mainly reported surveillance intervals that were too short (ie, overuse). The reason for underuse may be related to the increased attention to endoscopy demand in Canada with expanding wait lists $(22,23)$. Recently, it was shown that there is a significantly longer mean wait time than recommended for gastroenterology services, including colonoscopy, in Canada. For example, the average wait time for a screening colonoscopy was reported to be 201 days, and 272 days for CRC or adenoma surveillance. These observations underline the importance of appropriate timing of colonoscopy surveillance.

Regarding the specific clinical scenarios, several observations warrant discussion. This discussion can guide future research, but also guidelines' improvement projects.

First, in the case in which two hyperplastic polyps were found, it should be emphasized that the guidelines state that other screening modalities, apart from colonoscopy, would be appropriate for surveillance. This individual is regarded as an average-risk patient. None of the respondents considered other screening modalities in their answer, and the majority chose to offer the patient a surveillance colonoscopy. To control the demand for endoscopy, the use of other screening modalities should be considered in these nonadvanced cases.

In more advanced cases, such as villous adenoma, adenomas $>10 \mathrm{~mm}$ in size or polyps with HGD, the percentage of respondents deviating from the guidelines was higher. The reason might be that there is persistent controversy with respect to optimal management, particularly when dealing with the impact of villous histology and HGD on adenoma recurrence. Controversy exists because villous histology or HGD is not consistently found to be associated with an increased risk of adenoma recurrence; the risk of recurrence does not increase as much as for other factors such as the number and size of polyps; and high interobserver variability is present in determining size and histology $(9,24,25)$.

In the case of a 50-year-old woman with one villous adenoma $15 \mathrm{~mm}$ in size, $25 \%$ of the respondents recommended an interval shorter than recommended by the guidelines. The fact that this patient had two risk factors for recurrence (adenoma $>10 \mathrm{~mm}$ and villous histology) might have been the reason for physicians to shorten the surveillance interval. On the other hand, $12 \%$ of the respondents proposed surveillance at a longer interval than recommended, up to an interval of five years. Little is known about the additive risk of multiple risk factors, although a recent study found that the risk for adenoma recurrence doubled (hazard ratio 6.4) when both $\geq 3$ adenomas and advanced morphology were present (26). The shortened surveillance interval might reflect this uncertainty, but should be discouraged as long as definitive evidence for additive risk of multiple risk factors for recurrence is lacking.

Contrasting findings were found for the recommended surveillance intervals for patients with a family history of CRC. The large majority (92\%) recommended a correct surveillance interval in the case of a 45-year-old woman with one first-degree relative with CRC younger than 60 years of age. In contrast with this case, the case of a 52 -year-old man with one first-degree relative with CRC older than 60 years of age, only $41 \%$ of the respondents adhered to the guidelines. It should be mentioned that in this case, other screening modalities are also appropriate according to the AGA guidelines. However, none of the respondents stated that they would offer other screening tests, and the majority chose to offer surveillance colonoscopy within five years instead of the recommended 10 years. Moreover, $38 \%$ of the respondents stated that they followed the guidelines for this scenario, but did not give the correct recommendation. This suggests that colonoscopists are not entirely aware of the differences in 
guidelines for patients with a positive family history for CRC. The differences in surveillance recommendations for a positive family history (first-degree relative younger than 60 years of age or two first-degree relatives every five years colonoscopy, first-degree relative older than 60 years of age or two first-degree relatives every 10 years colonoscopy) make the guidelines hard to apply in daily clinical practice. Training and education of trainees and physicians in this area should be considered to improve compliance to the guidelines for surveillance in patients with a positive family history.

In the case of an 85-year-old man with one villous adenoma, only $23 \%$ of the respondents followed the guidelines. Fifty-eight per cent of the respondents recommended no surveillance at all, which is an option that should be considered when giving recommendations for surveillance colonoscopy to patients of this age. The starting age for screening colonoscopy is well-defined ( 50 years). However, the age to discontinue surveillance varies among recommendations. Recently, the CAG stated that persons older than 85 years of age should not be screened (27). No upper age-limit is given in the AGA recommendation (28). Future guidelines should take this into consideration.

Another interesting finding was that in the case of a 50-year-old woman with a piecemeal resection of a villous adenoma $15 \mathrm{~mm}$ in size, only $25 \%$ of the respondents adhered to the guidelines. This suggests that colonoscopists were not aware of the fact that complete removal should be verified both pathologically and endoscopically (29).

No clear guidelines were available in the case of a 55-year-old man with one villous adenoma $9 \mathrm{~mm}$ in size but inadequate bowel preparation. The recommendations in this case varied from "as soon as possible" up to an interval of five years. The majority $(43 \%)$ recommended FU after one year. It has been shown that a poor bowel preparation is associated with lower adenoma detection rates, but becasuse it is difficult to objectively rate the bowel preparation throughout the entire colon, recommendations for these patients are left to the clinician's discretion $(30,31)$.

The present study has several limitations. First, the response rate was low (36\%). Therefore, the results may not be representative of the actual practice of Canadian endoscopists and represent only a fraction of Canadian endoscopy practice. This low response rate is consistent with response rates reported in similar surveys $(32,33)$. However, the nonresponders did not differ significantly from responders with respect to sex or province, which may indicate that we obtained a representative sample. Furthermore, no exact information about the specific medical specialty of the responding CAG members was available. The observed response rate may partly be due to the fact that the survey was sent to all members and subspecialties, and pediatricians and hepatologists were not excluded. Despite the low response rate, the fact that colonoscopists from all Canadian provinces responded (data not shown), and experience in colonoscopy varied from one to 38 years, indicate that the study population is likely to be a good representation of the physicians performing colonoscopies in Canada. It should be noted, however, that only CAG members were included, and that the results do not represent the practice patterns of nonmembers.

Regarding study design, the clinical cases were presented in short sentences; colonoscopists may want to have more background information (such as health status, detailed family history, etc) to make their recommendation. In particular, colonoscopists were not provided with information about the location of the adenomas. Studies have shown that there may be a difference in the risk of recurrence between right- and left-sided adenomas, although none of the current guidelines incorporates this in their recommendations $(9,34)$. Colonoscopy has been shown to significantly reduce CRC-related mortality from distal CRC, while the number of deaths from proximal CRC was not significantly reduced $(35,36)$. These findings might impact colonoscopists' recommendations for surveillance intervals after polypectomy, and result in less confidence in the guidelines and, therefore, less adherence.
A final limitation might be that the CAG guidelines for CRC and adenoma surveillance refer to guidelines from the British Society of Gastroenterology and AGA, and do not make specific recommendations by themselves (37). The AGA guidelines have been discussed extensively above and used in the present study as they are commonly used in daily practice. Recently, the British Society of Gastroenterology published an update on its guidelines on screening and surveillance. However, no changes were made in the recommendations for surveillance of adenoma patients compared with 2002. These guidelines state that a patient with three or four small $(<10 \mathrm{~mm})$ adenomas at baseline should receive more vigilant surveillance at three years, patients with large $(>10 \mathrm{~mm})$ adenomas at one year, while all others should receive no surveillance or at five years. Baseline dysplasia or histology is not taken into account.

Because our survey was partly based on a previous survey used in the Netherlands, it should be noted that the Dutch guidelines used in that study are quite different (16). The Dutch guidelines only take the number of adenomas into account for determining the appropriate surveillance interval: patients with three or more adenomas are recommended to undergo surveillance colonoscopy after three years, while patients with one or two adenomas are recommended to undergo surveillance after six years. In the Dutch study, overuse of colonoscopic resources was mainly observed because many physicians took other adenoma characteristics such as histology and dysplasia into account (16). We found both overuse and underuse, the differences in results may be explained by the fact that physicians are now better aware of the increased risk of adenoma recurrence in certain circumstances.

\section{CONCLUSION}

The present study showed that the most recent guidelines on surveillance intervals for colorectal adenomatous polyps and CRC are not well incorporated in the practice patterns of Canadian colonoscopists. Assuming that guidelines are based on the most up-to-date and comprehensive evidence, compliance is expected to be high However, our data indicate that compliance with the most recent guidelines is low. Awareness of the surveillance guidelines needs to be raised and studies should be performed to determine how adherence to the guidelines can be improved. This will help to ensure that the limited resources available for CRC screening and surveillance are optimally used.

\section{REFERENCES}

1. Canadian Cancer Society's Steering Commity. Canadian Cancer Statistics 2010. Toronto: Canadian Cancer Society, 2010.

2. Hewitson P, Glasziou P, Watson E, Towler B, Irwig L. Cochrane systematic review of colorectal cancer screening using the fecal occult blood test (hemoccult): An update. Am J Gastroenterol 2008;103:1541-9.

3. Pignone M, Rich M, Teutsch SM, Berg AO, Lohr KN. Screening for colorectal cancer in adults at average risk: A summary of the evidence for the U.S. Preventive Services Task Force. Ann Intern Med 2002;137:132-41.

4. Winawer SJ, Zauber AG, Ho MN, et al. Prevention of colorectal cancer by colonoscopic polypectomy. The National Polyp Study Workgroup. N Engl J Med 1993;329:1977-81.

5. Leddin D, Hunt R, Champion M, et al. Canadian Association of Gastroenterology and the Canadian Digestive Health Foundation: Guidelines on colon cancer screening. Can J Gastroenterol 2004;18:93-9.

6. Levin B, Lieberman DA, McFarland B, et al. Screening and surveillance for the early detection of colorectal cancer and adenomatous polyps, 2008: A joint guideline from the American Cancer Society, the US Multi-Society Task Force on Colorectal Cancer, and the American College of Radiology. Gastroenterology 2008;134:1570-95.

7. West NJ, Boustiere C, Fischbach W, Parente F, Leicester RJ. Colorectal cancer screening in Europe: Differences in approach; similar barriers to overcome. Int J Colorectal Dis 2009;24:731-40. 
8. Lieberman DA, Weiss DG, Harford WV, et al. Five-year colon surveillance after screening colonoscopy. Gastroenterology 2007;133:1077-85.

9. Martinez ME, Baron JA, Lieberman DA, et al. A pooled analysis of advanced colorectal neoplasia diagnoses after colonoscopic polypectomy. Gastroenterology 2009;136:832-41.

10. Rex DK, Petrini JL, Baron TH, et al. Quality indicators for colonoscopy. Am J Gastroenterol 2006;101:873-85.

11. Vijan S, Inadomi J, Hayward RA, Hofer TP, Fendrick AM. Projections of demand and capacity for colonoscopy related to increasing rates of colorectal cancer screening in the United States. Aliment Pharmacol Ther 2004;20:507-15.

12. Nelson DB, McQuaid KR, Bond JH, Lieberman DA, Weiss DG, Johnston TK. Procedural success and complications of large-scale screening colonoscopy. Gastrointest Endosc 2002;55:307-14.

13. Panteris V, Haringsma J, Kuipers EJ. Colonoscopy perforation rate, mechanisms and outcome: From diagnostic to therapeutic colonoscopy. Endoscopy 2009;41:941-51.

14. Mulder SA, Van Leerdam ME, Ouwendijk RJ, Bac DJ, Giard RW, Kuipers EJ. Attendance at surveillance endoscopy of patients with adenoma or colorectal cancer. Scand J Gastroenterol 2007;42:66-71.

15. Knopf KB, Warren JL, Feuer EJ, Brown ML. Bowel surveillance patterns after a diagnosis of colorectal cancer in Medicare beneficiaries. Gastrointest Endosc 2001;54:563-71.

16. Mulder SA, Ouwendijk RJ, van Leerdam ME, Nagengast FM, Kuipers EJ. A nationwide survey evaluating adherence to guidelines for follow-up after polypectomy or treatment for colorectal cancer. J Clin Gastroenterol 2008;42:487-92.

17. Mysliwiec PA, Brown ML, Klabunde CN, Ransohoff DF. Are physicians doing too much colonoscopy? A national survey of colorectal surveillance after polypectomy. Ann Intern Med 2004;141:264-71.

18. Saini SD, Nayak RS, Kuhn L, Schoenfeld P. Why don't gastroenterologists follow colon polyp surveillance guidelines?: Results of a national survey. J Clin Gastroenterol 2009;43:554-8

19. Cabana MD, Rand CS, Powe NR, et al. Why don't physicians follow clinical practice guidelines? A framework for improvement. JAMA 1999;282:1458-65.

20. Berwick DM. Disseminating innovations in health care. JAMA 2003;289:1969-75.

21. Burke CA, Issa M, Church J. A nationwide survey of postpolypectomy surveillance colonoscopy: Too many too soon! Gastroenterology 2005;128:A-566.

22. Leddin D, Bridges RJ, Morgan DG, et al. Survey of access to gastroenterology in Canada: The SAGE wait times program. Can J Gastroenterol 2010;24:20-5.

23. Paterson WG, Depew WT, Pare P, et al. Canadian consensus on medically acceptable wait times for digestive health care. Can J Gastroenterol 2006;20:411-23.

24. Saini SD, Kim HM, Schoenfeld P. Incidence of advanced adenomas at surveillance colonoscopy in patients with a personal history of colon adenomas: A meta-analysis and systematic review. Gastrointest Endosc 2006;64:614-26.

25. Terry MB, Neugut AI, Bostick RM, Potter JD, Haile RW, Fenoglio-Preiser CM. Reliability in the classification of advanced colorectal adenomas. Cancer Epidemiol Biomarkers Prev 2002;11:660-3.

26. van Heijningen E-MB, Lansdorp-Vogelaar I, de Jonge V, Steyerberg EW, Kuipers EJ, van Ballegooijen M. Risk factors for metachronous advanced colorectal neoplasia in a cohort of adenoma patients: Advanced morphology and multiplicity. Gastroenterology 2011;140:S183.

27. Leddin DJ, Enns R, Hilsden R, et al. Canadian Association of Gastroenterology position statement on screening individuals at average risk for developing colorectal cancer: 2010. Can J Gastroenterol 2010;24:705-14.

28. Regula J, Kaminski MF. Targeting risk groups for screening. Best Pract Res Clin Gastroenterol 2010;24:407-16.

29. Pabby A, Schoen RE, Weissfeld JL, et al. Analysis of colorectal cancer occurrence during surveillance colonoscopy in the dietary Polyp Prevention Trial. Gastrointest Endosc 2005;61:385-91.

30. Froehlich F, Wietlisbach V, Gonvers JJ, Burnand B, Vader JP. Impact of colonic cleansing on quality and diagnostic yield of colonoscopy: The European Panel of Appropriateness of Gastrointestinal Endoscopy European multicenter study. Gastrointest Endosc 2005;61:378-84.

31. Harewood GC, Sharma VK, de Garmo P. Impact of colonoscopy preparation quality on detection of suspected colonic neoplasia. Gastrointest Endosc 2003;58:76-9.

32. MacNeil-Covin L, Casson AG, Malatjalian D, Veldhuyzen van Zanten S. A survey of Canadian gastroenterologists about the management of Barrett's esophagus. Can J Gastroenterol 2003;17:313-7.

33. Wallace TM, Veldhuyzen van Zanten SJ. Frequency of use and standards of care for the use of azathioprine and 6-mercaptopurine in the treatment of inflammatory bowel disease: A systematic review of the literature and a survey of Canadian gastroenterologists. Can J Gastroenterol 2001;15:21-8.

34. Martinez ME, Sampliner R, Marshall JR, Bhattacharyya AK, Reid ME, Alberts DS. Adenoma characteristics as risk factors for recurrence of advanced adenomas. Gastroenterology 2001;120:1077-83.

35. Singh H, Nugent Z, Demers AA, Kliewer EV, Mahmud SM, Bernstein CN. The reduction in colorectal cancer mortality after colonoscopy varies by site of the cancer. Gastroenterology 2010;139:1128-37.

36. Brenner H, Hoffmeister M, Arndt V, Stegmaier C, Altenhofen L, Haug U. Protection from right- and left-sided colorectal neoplasms after colonoscopy: Population-based study. J Natl Cancer Inst 2010;102:89-95.

37. Atkin WS, Saunders BP. Surveillance guidelines after removal of colorectal adenomatous polyps. Gut 2002;51(Suppl 5):6-9. 


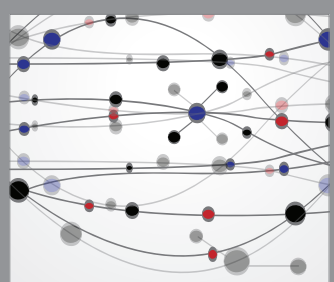

The Scientific World Journal
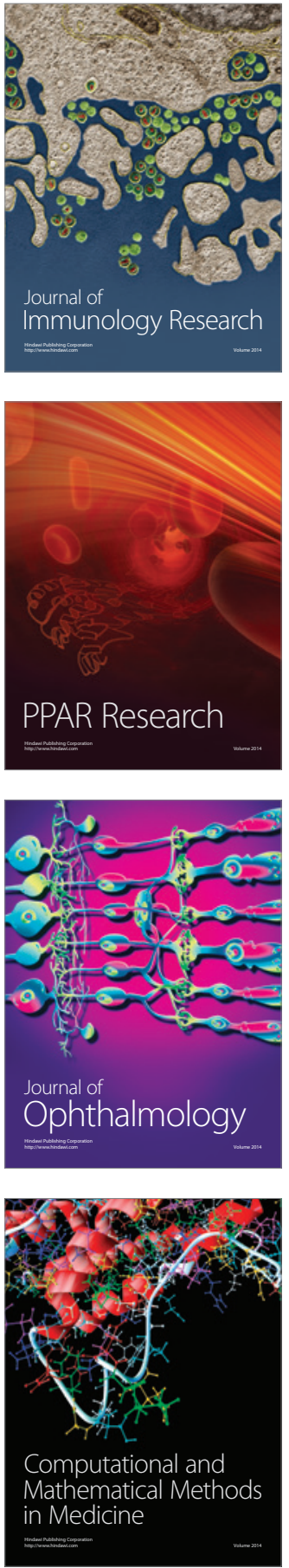

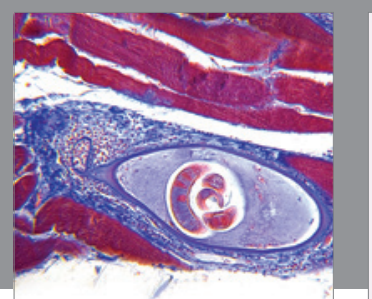

Gastroenterology Research and Practice

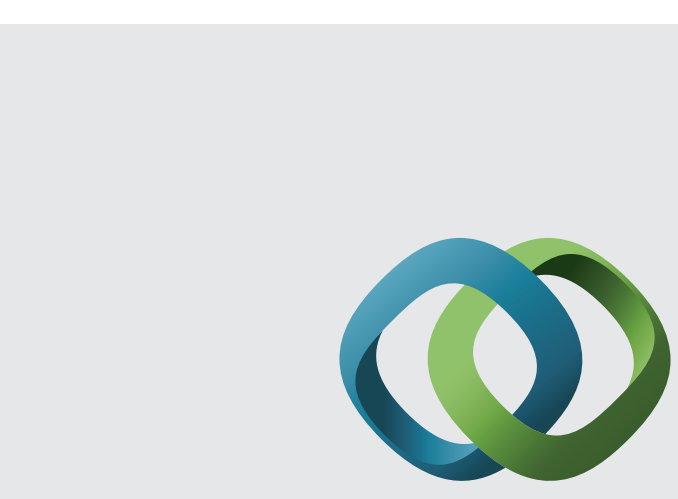

\section{Hindawi}

Submit your manuscripts at

http://www.hindawi.com
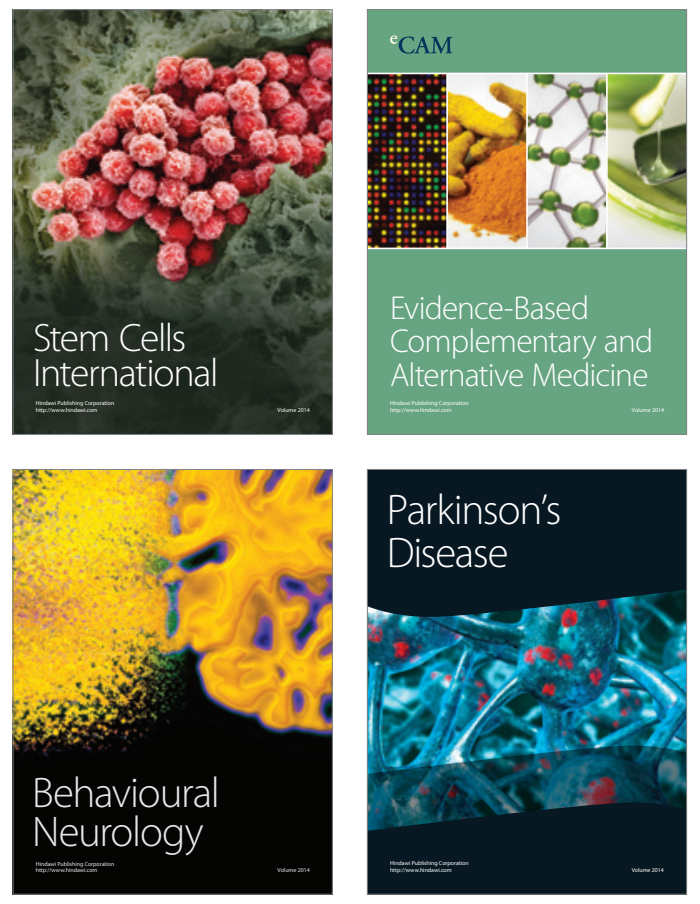
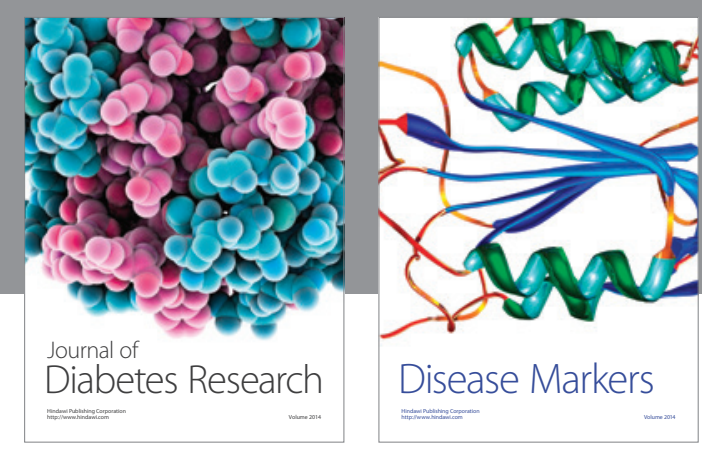

Disease Markers
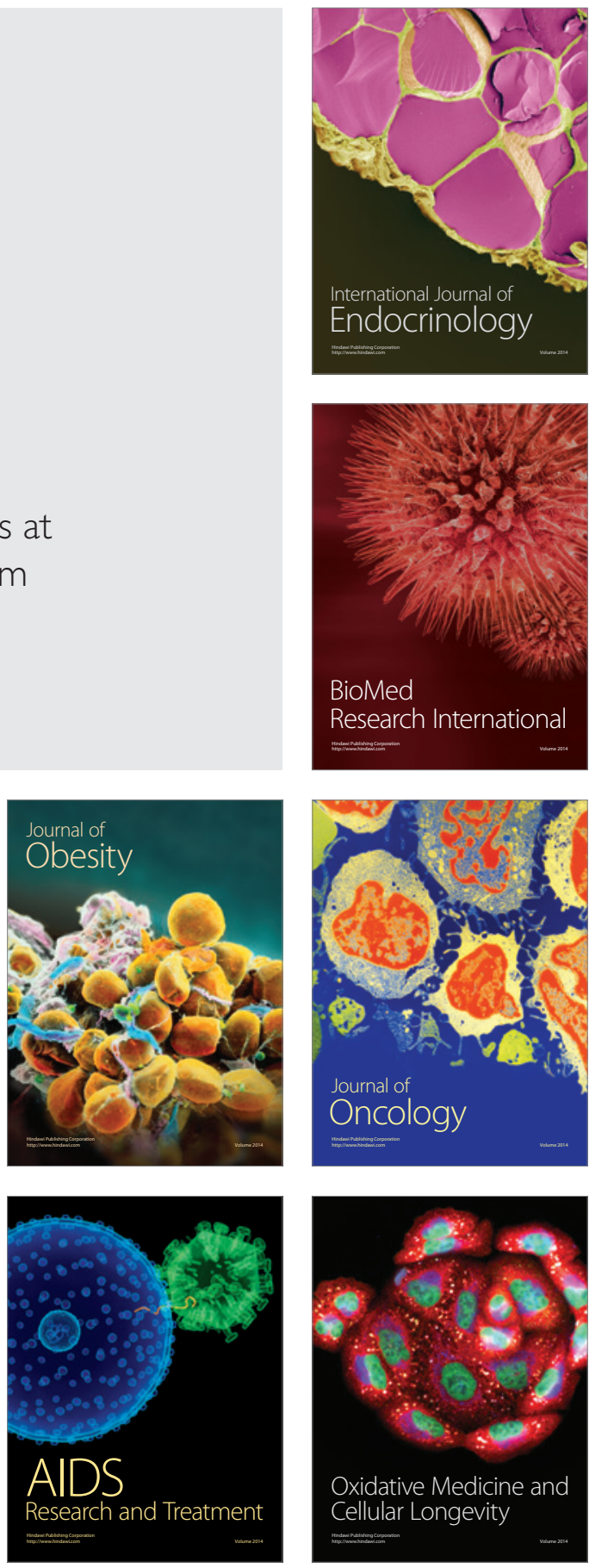